\title{
Social Capital, Geography, and Survival: Gujarati Immigrant Entrepreneurs in the U.S. Lodging Industry
}

\author{
Arturs Kalnins \\ School of Hotel Administration, Cornell University, Statler Hall 454D, Ithaca, New York 14853-6902, atk23@cornell.edu \\ Wilbur Chung \\ R.H. Smith School of Business, University of Maryland, 3417 Van Munching Hall, College Park, Maryland 20742-1815, \\ wchung@rhsmith.umd.edu
}

\begin{abstract}
Tmmigrant entrepreneurs often rely on their group's local social capital in their new home market to estab1 lish and maintain their businesses. In particular, immigrant entrepreneurs with few resources of their own receive help from those possessing more resources. Supporting these arguments using the empirical setting of Gujarati immigrant entrepreneurs in the lodging industry, we find that the likelihood of survival of an immigrant entrepreneur's hotel increases when surrounded by higher counts of branded hotels (representing high-resource establishments) owned by individuals from their ethnic group but is unaffected by unbranded motels (representing low-resource establishments) owned by members of their ethnic group or by branded hotels owned by individuals from other ethnic groups. These results isolate and reinforce the importance of social capital not only for immigrant entrepreneurs but also more generally for any entrepreneurs belonging to ethnic, professional, religious, or social groups.
\end{abstract}

Key words: social capital; immigrant entrepreneurs; franchising; survival; hotels

History: Accepted by Scott Shane, guest editor; received April 1, 2004. This paper was with the authors

3 months for 1 revision.

\section{Introduction}

Individuals that found and operate their own ventures make up over $13 \%$ of the U.S. workforce (Hamilton 2000) and have long been acknowledged as vital for the dynamic renewal of capitalist economies (Schumpeter 1934, Shane and Venkatraman 2000). Entrepreneurs often require social resources to found these ventures (Aldrich and Zimmer 1986). Yet, Putnam $(1995,2000)$ has argued that a decrease in civic involvement by Americans has reduced the nation's stock of localized social capital. Among the negative outcomes of this trend, Putnam (2000, p. 384) argued, is the possible end of "an arc of creativity and entrepreneurship." An implication of Putnam's argument is that groups that do continue to engage in local interactions and maintain their social capital should be particularly successful in entrepreneurial ventures. Immigrant entrepreneurs by necessity rely heavily on local social capital in their new home market (e.g., Portes and Sensenbrenner 1993). For this reason they are likely to play an important ongoing role in the renewal of modern capitalist economies and are worthy of ongoing attention from scholars in business strategy and entrepreneurship.

While immigrant entrepreneurs have been studied extensively (e.g., Light 1972, Bonacich and Modell
1980, Aldrich et al. 1984), performance of their ventures has remained under-studied. Similar to arguments made by Lincoln et al. (1996) for the case of the Japanese keiretsu business groups, we argue that the least prosperous immigrant entrepreneurs should benefit the most from the social capital of their ethnic group. In addition, we argue that assistance of immigrant group members is contingent upon geographic location; entrepreneurs with few resources are more likely to flourish proximately to the establishments of high-resource members of the same ethnic group. Based on this same logic, we explore the possibility that immigrant entrepreneurs seek out sites with high-resource countrymen in the vicinity to found their ventures.

Even if no immigrant entrepreneurs existed within an industry, a geographic location with an agglomeration of related businesses may enhance firm performance (Marshall 1920), and in particular, the performance of firms with few resources of their own (Shaver and Flyer 2000). Given that an industry does contain immigrant entrepreneurs, when low-resource immigrant entrepreneurs enjoy superior performance in the vicinity of high-resource members, is it the ethnic/regional group membership or simple agglomeration benefits that enhance performance? To dis- 
tinguish benefits of social capital from those of simple agglomeration, we compare the effects of proximate high-resource ethnic group members and highresource nonmembers (mostly from the native population of the same industry) on survival of immigrant establishments that lack their own resources. We also compare the effect of proximate high-resource immigrant group establishments on the survival of low-resource group member establishments with their effect on the survival of low-resource establishments owned by nonmembers. Only if both the contributors and recipients of benefits turn out to be members of the immigrant group would we conclude that we have identified a benefit of social capital rather than an agglomeration benefit available to all.

Our empirical setting is the lodging industry, an industry in which previous work has found benefits of agglomeration (e.g., Baum and Haveman 1997, Canina et al. 2005, Chung and Kalnins 2001). Interestingly, this industry also contains a large group of immigrant entrepreneurs: hotel owners from the Indian state of Gujarat. Gujaratis own a large percentage of hotels across the United States. In Texas in 1999, Gujaratis owned over 30\% of hotels unaffiliated with national branded chains. Further, as franchisees, they owned over $50 \%$ of properties affiliated with Days Inn, Econolodge, Comfort Inn, and Super Eight and a substantial proportion of the other major branded U.S. hotel chains.

In studying Gujarati immigrant entrepreneurs, this paper follows an earlier work (Kalnins and Chung 2001). That paper treated all Gujarati owners as a homogeneous group and found that Gujarati hotel owners cluster at a broad regional (multicounty) level, but not at a more local (zip code) level. The paper found no implications for pricing or revenue of a high Gujarati presence in a zip code. We build on that work by (1) analyzing establishment-level survival (important for capturing cost-side benefits of social capital), and (2) analyzing the importance of resource heterogeneity within an immigrant entrepreneur community. This more detailed analysis yields important evidence of social capital not visible when treating all Gujarati owners as a homogeneous group.

\section{Immigrant Entrepreneurs and Social Capital}

\subsection{Literature Review}

The social structure of an immigrant entrepreneur group provides motivation for a member's contribution to the social capital of the group even in the absence of direct incentives. Members may have a motivation to contribute to the group either due to a principled sense of shared values and shared destiny, or due to enforceable trust caused by an instrumental fear of reputation loss (Portes and Sensenbrenner 1993). Importantly, contributions occur among group members without reciprocity-a member may help another out financially without expecting repayment in kind.

To develop our hypotheses, we focus on the cooperative behavior that takes place among immigrant entrepreneurs, especially behavior not expecting reciprocity. In such cases, the benefits from group membership can be attributed to social capital (see Bourdieu 1986 and Coleman 1990 for the seminal work on this topic). Synthesizing many definitions of social capital, Adler and Kwon (2002, p. 23) state:

Social capital is the goodwill available to individuals and groups. Its source lies in the structure and content of the actor's social relations. Its effects flow from the information, influence, and solidarity it makes available to the actor.

The creation of greater stocks of social capital is facilitated by certain social structures. The two types of social structure that underlie immigrant entrepreneur groups are family relations and common ethnic (or regional) backgrounds. Common ethnic background also motivates immigrant entrepreneurs to help others within their group (e.g., Light 1972, Bonacich and Modell 1980). Immigrant entrepreneurs often cluster in a particular industry in their host nation, enabling them to further cooperate and generate social capital. Scholars have identified cases of Chinese laundries in California (Ong 1981), Gujarati "cornershops" in Great Britain (Aldrich et al. 1984), as well as the Gujarati hotel owners in the United States first studied by Kalnins and Chung (2001) and analyzed further in this paper.

Portes and Sensenbrenner (1993) discuss shared values and enforceable trust as important sources of social capital in the context of immigrant entrepreneurs. Fledgling immigrant entrepreneurs are likely to rely on the social capital of their group for support, because they may not have access to local (and typically indigenously operated) supporting institutions such as banks. As a substitute for the local supporting institutions available to native entrepreneurs, institutions such as the rotating credit association have been often raised as key outcomes of shared values and enforceable trust of immigrant entrepreneur groups (e.g., Geerz 1962, Light 1972). In the rotating credit association, members are willing to loan money without any legally enforceable contract or collateral. While a member of the credit association could easily renege on future payments to others after receiving a loan, the trust is enforceable because the group members are afraid of the reputation loss they would face if they reneged. Portes and Sensenbrenner 
(1993) present other examples resulting from enforceable trust; for example, loans made to Cuban and Dominican entrepreneurs by members of their ethnic community are paid back with a large certainty despite their "paperless" nature. The entrepreneur's reputation is the only collateral necessary.

Our discussions with Gujarati hotel owners consistently brought out similar anecdotes of help within the immigrant entrepreneur group. We interviewed 16 Gujarati hotel owners in Texas by telephone for 20-30 minutes each. The interviews were structured but did not contain any leading questions. For example, we simply asked, "In what ways would the management of your hotel differ if you had no close contacts with other hotels?" All but one emphasized the role of other group members in helping them get started as well as in their continued operations. While in most cases, there were extended family or friendship ties to those that helped the most, in three cases there were none, a point that was emphasized with no prompting from us. These three owners stated that other Gujaratis who did not know them personally (there were not even mutual friendships) helped them significantly, loaning them money and providing information and supplies. One Gujarati owner of an unbranded motel told us:

[A Gujarati owner of a branded chain hotel] helped me a lot. In franchise, you have to replace furniture, et cetera, regularly. So, instead of selling it, he gave me all the stuff he was supposed to sell... People don't give away such things for free. He gave me all this just because I was from the place near to his native. We don't have a relation. We met for the first time... [He] helped me without any expectations. I am an ordinary person. What would he get from me?

\subsection{Hypotheses}

The access to social capital by immigrant entrepreneurs brings us to our "baseline" hypothesis regarding establishment survival. The benefits of social capital mentioned above, such as access to capital and information, lower the immigrant entrepreneurs' costs and thus should help their establishments survive. The rotating credit association, for example, lowers the immigrant entrepreneurs' cost of capital, while the donation of supplies (such as the donation of furniture in the quote above) reduces their upfront fixed costs. Native entrepreneurs may have compensating access to the local infrastructure (e.g., banks), but this access typically requires some resources, implying that the immigrant entrepreneurs should have a baseline survival advantage over their native lowresource counterparts.

Hypothesis 1. Among the establishments of owners without resources, those operated by owners belonging to an immigrant entrepreneur group will have a lower probability of failure than establishments operated by nonmembers.

Further, we expect variation in the contributions to and the benefits from social capital made and enjoyed by group members, leading to heterogeneous survival advantages within a group. Adler and Kwon (2002) propose that motivation, opportunity, and ability to contribute to social exchange (i.e., providing a favor with no explicit quid pro quo) are necessary conditions for social capital to be generated. We expect that immigrant entrepreneurs have motivation to contribute to the social capital of their group because of shared values and enforceable trust, although some group members may have more opportunities and greater ability to contribute to social capital, that is, to help others within their group.

Opportunity to help other group members should be enhanced by geographical proximity. Proximity has been shown to facilitate transfer of information between subsidiaries of the same firm (Adams and Jaffe 1996) and enable face-to-face contact (McDermott and Taylor 1982, pp. 73-74). Through the frequent and personal contact facilitated by proximity, group members are able to receive tacit information regarding which other members actually need help and what type of help the other members may need. With such knowledge, proximate group members will have greater opportunity to help each other versus more distant members who might also have similar motivation and ability to help, but not knowledge of the opportunity to help.

Immigrant entrepreneurs' abilities to contribute to social capital are enhanced by the resources they possess. Members lacking resources are less likely to be able to help others in their group even when they have the motivation and the opportunity to do so (e.g., Portes and Sensenbrenner 1993). While group members possessing resources are less likely to help their low-resource counterparts for instrumental reasons as those lacking resources are unlikely to be to be able to reciprocate in the future, the members with resources are likely to help for reasons of principle. As established members likely feel a sense of shared values and destiny with those who have not been as successful, they are likely to help even in the absence of the vaguest possibility of reciprocation.

Overall, a combination of resource abundance and geographical proximity to those who lack resources will enhance the amount of social capital that a group member can contribute. Conversely, a lack of resources combined with proximity to those possessing resources allows a firm to enjoy the benefits of social capital. If the effects of social capital sufficiently reduce costs (and in some cases, increase revenues as well) to have an impact on likelihood of establishment survival, we should observe three related results. 
First, low-resource establishments of immigrant entrepreneur group members will be less likely to fail than will those of nongroup members when in the vicinity of high-resource group members. While the low-resource establishments of nonmembers provide an important comparison for survival rates, the common ethnic or regional background is required for firms to have the ability to receive social capital benefits. Thus, this is not a generic spillover effect that would apply industrywide to all proximate firms with few resources (e.g., Shaver and Flyer 2000, Chung and Kalnins 2001).

Second, this survival-enhancing effect of proximate high-resource group members will be greater than a beneficial effect that may arise from the presence of high-resource nongroup members. While all proximate high-resource firms have the opportunity to help immigrant entrepreneurs that lack resources, only those sharing their ethnic background have the motivation to do so because of shared values and a possible gain in reputation within their community.

Third, immigrant entrepreneurs possessing roughly equal resource stocks may be able to help each other survive, but less so than the rich can help the poor. For example, when neither proximate immigrant entrepreneur has resources, they are less likely to help each other survive because they often lack the ability. When both entrepreneurs possess substantial resources, their common ethnicity is unlikely crucial for survival of their business establishments as their own resources are of primary importance. These three related effects are formalized as Hypotheses 2a-2c, and are also summarized in Table 1.

Hypothesis 2a (Group Membership Matters). The failure rate of low-resource immigrant entrepreneur group member establishments will be reduced more than will the failure rate of low-resource nonmember establishments by the proximate presence of high-resource group member establishments.

Hypothesis 2в (Group Membership of Proximate OTHERS MATTERS). The failure rate of low-resource immigrant entrepreneur group member establishments will be

Table 1 Effect on Low-Resource Hotels' Failure Rates of Proximity to Other Hotels

\begin{tabular}{lcc}
\hline & $\begin{array}{c}\text { Effect on } \\
\text { low-resource } \\
\text { member }\end{array}$ & $\begin{array}{c}\text { Effect on } \\
\text { low-resource } \\
\text { nonmember }\end{array}$ \\
\hline $\begin{array}{l}\text { Proximity to } \\
\text { High-resource member }\end{array}$ & $\mathrm{A}$ & \\
High-resource nonmember & $\mathrm{C}$ & $\mathrm{B}$ \\
Low-resource member & $\mathrm{E}$ & $\mathrm{D}$ \\
Predictions & $\mathrm{A}<\mathrm{B}$ (Hypothesis 2a) \\
& $\mathrm{A}<\mathrm{C}$ (Hypothesis 2b) \\
& $\mathrm{A}<\mathrm{E}$ (Hypothesis 2c) \\
\hline
\end{tabular}

reduced more by the proximate presence of high-resource member establishments than by the proximate presence of high-resource nonmember establishments.

Hypothesis 2c (Resources of Proximate Group MEMBERs MATTER). The failure rate of low-resource immigrant entrepreneur group member establishments will be reduced more by the proximate presence of high-resource member establishments than by the proximate presence of other low-resource member establishments.

If the presence of high-resource group members is beneficial to the group members without their own resources, as argued above, then we may observe low-resource group members acting to increase their ability to enjoy benefits of the group's social capital. Sociologists have maintained that actors attempt to gain social capital through purposeful actions (Bourdieu 1986, Coleman 1990). While immigrant entrepreneurs obtain initial membership in the group merely through their ethnic origins, they can choose their level of embeddedness within the group by locating geographically in areas with many group members or in other areas with just a few. By locating in an area with many group members, an immigrant entrepreneur provides incumbent members with the opportunity to help the fledgling venture.

An alternative logic that predicts the same pattern in location choices is that of mimetic market entry. Haveman (1993) argues that market entrants follow high-status firms into new markets. Highresource immigrant entrepreneur group members are likely considered to be of high status, implying that entrepreneurs would be more likely to locate in their vicinity to appear more similar to the high-resource group members. While a distinction between the purposeful and mimetic arguments is outside the scope of this paper, these logics suggest very similar hypotheses. These hypotheses are analogous to those for survival presented as Hypotheses 2a-2c: group members without resources will be significantly more likely to locate in the vicinity of high-resource group members than will low-resource nongroup members.

Hypothesis 3a (Group Membership Matters). The probability of low-resource immigrant entrepreneur group members choosing a location with proximate highresource member establishments will be greater than that of low-resource nonmember establishments choosing such a location.

Hypothesis 3в (Group Membership of Proximate OTHERS MATTERs). The probability of low-resource immigrant entrepreneur group members choosing a location with proximate high-resource member establishments will be greater than their probability of choosing a location with proximate high-resource nonmember establishments.

Hypothesis 3c (Resources of Proximate Group Members MatTer). The probability of low-resource 
immigrant entrepreneur group members choosing a location with proximate high-resource member establishments will be greater than their probability of choosing a location with other proximate low-resource member establishments.

\section{Research Design}

\subsection{Research Setting: Gujarati-Owned Hotels}

To test the hypotheses above, we investigate an economically significant case of immigrant entrepreneurship: Gujarati hotel owners in the United States. Gujarat is a western coastal state in India whose main industry is agriculture. Yet, in the United States, Gujaratis have mainly become hotel owners. While Gujaratis run hotels in all 50 states, they are particularly prevalent along the interstates of the "sun belt" that stretches from Virginia to California (Millman 1997, p. 145). Concentrations of Gujarati hotels exist in Georgia, Florida, California, and Texas. One Gujarati hotel owner that we interviewed estimated that "in Dallas [there are] over 400 Gujarati families out of which $95 \%$ are in the hotel business, either working for a hotel or [owning] a motel." Table 2 shows the large and growing Gujarati presence in the Texas lodging industry. As shown, Gujaratis began to acquire and found unbranded motels in the late 1970s. They became involved in branded chains as franchisees only in the 1990s.

Millman (1997) chronicles the rise of the Gujaratiowned hotels. When India was a British colony, Gujaratis wound up in England or in African colonies such as Malawi, Zambia, and Uganda. Many Gujaratis were expelled from Uganda during the brutal reign of dictator Idi Amin in the 1970s, who also confiscated their businesses. Fleeing with limited savings, these Indian expatriates searched for suitable destinations. These Indian expatriates and subsequent Indian immigrants found nonluxury hotels in the United States to be an attractive business opportunity for several reasons. First, entry barriers are low.

Table 2 New Foundings and Acquisitions by Date

\begin{tabular}{lccccc}
\hline & \multicolumn{2}{c}{ Unbranded motels } & & \multicolumn{2}{c}{ Branded chain hotels } \\
\cline { 2 - 3 } & Non-Gujarati & Gujarati & & Non-Gujarati & Gujarati \\
\hline Before 1970 & 51 & 2 & & 25 & 0 \\
$1970-1974$ & 41 & 5 & & 22 & 0 \\
$1975-1979$ & 110 & 61 & & 37 & 8 \\
$1980-1984$ & 166 & 178 & & 128 & 6 \\
$1985-1989$ & 339 & 171 & & 390 & 28 \\
$1990-1994$ & 361 & 298 & & 461 & 128 \\
$1995-1999$ & 207 & 225 & & 778 & 351 \\
\hline
\end{tabular}

Notes. This table includes no information about hotels that closed down before 1990. In the pre-1990 period, only the most recent acquisition date is known. The same establishment may be counted several times in this table, once for every ownership transfer. Nonbranded hotels include only those with the words "motel" or "motor hotel" or "motor inn" in their name.
With an investment of $\$ 40,000$, the displaced could secure immigrant status in the United States. With a $\$ 40,000$ investment, choice was limited to small establishments such as diners or roadside motels. Rural motels were often preferred because they provide both a business opportunity and a place of residence. Operating restaurants was not palatable for many Gujaratis, because as Hindus they were uncomfortable handling meat. Contagion further increased the size of the Gujarati hotel-owner community. Much like the format adoption of radio stations described in Greve (1995), the Gujaratis' likelihood of entering the lodging industry was much higher than that for other entrepreneurs, due to contagion. Additional descriptive information about the Gujarati hotel owner phenomenon can be found in Kalnins and Chung (2001).

Gujarati hotel owners are a particularly appropriate immigrant entrepreneur group with which to test our hypotheses for two reasons. First, substantial amounts of social capital appear to be generated within the Gujarati hotel-owner community. The Gujarati hotel owners provide each other with solidarity and information, considered by Adler and Kwon (2002) to be two central benefits of social capital. Both of these benefits reduce costs and should thus increase the likelihood of establishment survival. We mentioned earlier a case of a Gujarati branded hotel owner giving away his used furniture to a Gujarati he had never met. Other similar anecdotes strengthen this point (see Greensboro News and Record 1995, p. E1): "Everybody thinks like a family," said a Gujarati franchisee of a Red Carpet Inn in North Carolina. "We try to help each other... established innkeepers can advise and support newcomers. When times are tight, they'll loan each other money." Regarding exchange of information, he adds, "The Indian immigrants will share information with each other about which banks offer the lowest rates on mortgages. They'll spread among themselves the names of customers who have stiffed them on a room bill." Gujaratis also act collectively, he notes, stating, "To save money, they'll join forces to buy televisions and other hotel equipment in bulk."

Second, Gujarati hotels largely serve the same population as their indigenously owned counterparts, allowing us to make performance comparisons and tease apart the social capital explanation from the agglomeration explanation for any performance benefits. The native population may also develop social capital, of course, but time and repeated interactions are necessary for trust to develop (e.g., Gulati 1995). The Gujaratis likely enjoy social capital from the time of their arrival. Immigrant/native comparisons would be more difficult in cases where immigrant entrepreneurs mainly serve "enclave economies," that is, customers of their own ethnic background (see, e.g., Aldrich and Waldinger 1990, Bates 1994, 
Uzzi 1996), or when they function as "middlemen entrepreneurs," such as the case of Korean-owned shops in low-income areas (Light and Bonacich 1988). Relatedly, the fact that Gujaratis are not highly concentrated in narrow geographical enclaves also reduces the likelihood that Gujaratis are each other's primary competition, which can serve to undermine the benefits of the group's social capital (Aldrich and Waldinger 1990).

\subsection{Data}

Our data includes all lodging establishments operating in Texas at any time between 1990-1999 inclusive. The raw data comes from the Texas State Government Comptroller's Office, Hotel Tax Permit File. Every establishment that receives income from room rental must provide location and ownership data. These data include a hotel's name, opening date (and closing date if applicable), street address, owner name, owner location, and size in rooms. Owner name consists of a corporation name or the name of a person. Earlier versions of this data set were used by Kalnins and Chung (2001) and Chung and Kalnins (2001).

The lodging industry is an ideal setting for this study because branded chain affiliation is an easily observable indicator that a firm possesses resources and has the ability to contribute to social capital. Chain-affiliated hotels will be able to attract more customers and charge premium prices because of branding (Ingram 1996) and thus will accumulate more resources. Hotels of the branded chains also have significantly higher revenues than unbranded hotels (Chung and Kalnins 2001).

The most prosperous Gujarati hotel owners have become franchisees of several large American chains. In 1999, Gujaratis owned 46 of 138 Best Westerns in Texas, 69 of 102 Comfort Inns, 78 of 126 Days Inns, 22 of 30 Econolodges, and 55 of 84 Super Eight hotels, and also have a nontrivial presence among other franchised chains. We note that the Gujaratis dominate primarily in the lower-tier segment of branded hotels. In 1999, Gujaratis owned 287 low-tier branded chain hotels (one- or two-star brands such as Days Inn and Econolodge), and 143 higher-tier hotels (threestar brands such as Holiday Inn). For non-Gujaratis, these numbers are 418 and 683, respectively. Further, even within each branded chain, the Gujaratis have lower prices. Based on a 1999 pricing survey of a cross-section of 797 branded chain hotels, Gujarati owners charged \$3.94 less per room per night, even after controlling for brand. Implications of these differences are discussed in $\S 4$.

The lodging industry also contains a clearly identifiable subset of firms that likely possess the fewest resources: hotels with the words "motel" or "motor hotel" or "motor inn" in the business name but that are not affiliated with any franchised chain. By analyzing only the subset of hotels unaffiliated with branded chains with "motel" in their name, we exclude other unbranded properties such as upscale bed-and-breakfasts or resort lodges. ${ }^{1}$ Gujaratis owned 612 of 1,140 unbranded motels in existence in Texas at the end of 1999. Our interviews confirmed that the owners of motels unaffiliated with national chains possessed few resources. Several told us that they operated such motels specifically because they lacked the funds to buy a larger property of the quality necessary for branded chain affiliation. The data presented in Table 2 confirm the story of evolution of Gujarati hotel ownership from unbranded motels in the late 1970s and 1980s when the Gujaratis first arrived in the United States with few resources, to branded chain hotels via franchising in the 1990s after many Gujaratis had the opportunity to accumulate resources.

\subsection{Methods}

We tested Hypotheses 1 and 2a-2c using event history analysis. Specifically, we used parametric hazard models, which require that a functional form for the transition rates be specified. We estimated regressions using the exponential, Gompertz and Weibull forms, along with the Cox model that does not require the specification of form. Because our results did not differ based on the model used, we present results using the widely-used exponential model. The exponential form assumes that the instantaneous transition from origin state (active establishment) to destination state (establishment-level failure) at time $t$ does not depend on time $t$, but depends only on covariates. The general form of the model is

$$
r(t)=\exp \left(\beta^{\prime} X\right),
$$

where $r$ is the instantaneous transition or "hazard" rate, $X$ is a vector of covariates, and $\beta$ is the vector of coefficients. Because the values of all our covariates of theoretical interest change over time, we split the life histories of all establishments into yearly spells, and for each spell set all covariates to their values at the beginning of that year (see, e.g., Ingram and

\footnotetext{
${ }^{1}$ We analyzed only the survival of unbranded motels, but not of branded chain hotels, due to insufficient failure. Only 15 failures among the Gujarati-owned chain hotels took place in the 1990s. We did analyze "survival as a branded hotel" for all branded hotels, where an ex-branded hotel that continues to operate as unbranded is treated as a failure. Using this definition, 109 of 837 branded hotels rated two stars by the American Automobile Association (AAA) did not survive. We found that a Marshallian agglomeration benefit appeared to exist for two-star hotels in the vicinity of any three-star hotels, roughly of equal size for both Gujarati and nonGujarati two-star hotels. There was no indication of a social capital effect.
} 
Baum 1997). The parameters were then estimated by the method of maximum likelihood.

As mentioned earlier, many of the motels were in business before 1990, meaning that part of the sample is left-truncated-establishments that entered and exited before 1990 are not in the sample. Including establishments founded before 1990 but exiting after 1990 in the analysis does not cause left-censoring problems because the Texas data set contains information about the founding dates, even if those are before 1990. For example, the event history model will only analyze a motel founded in 1985 with others that have survived until the fifth year. It will never be directly compared to motels in the first four years after founding. Thus, the problems of left-censoring are avoided. See Guo (1993) and Stata Corp. (2001, pp. 441-446) for extensive discussions.

The dependent variable for the event history analysis is motel survival. Motels are considered survivors as long as they remain open for business. They are "at risk of failure" until they have permanently closed down. We do not consider motels to have failed in any way merely due to changes of ownership or "doing business as" name.

Hypotheses 3a-3c, the determinants of location choice, are tested using the conditional logit model for discrete choice-when an actor chooses from among a set of options. The conditional logit is commonly used in studies of location choice in the fields of strategy and organization theory (e.g., Greve 2000, Powell et al. 2004, Shaver and Flyer 2000). An extensive general description can be found in Greene (1998, pp. 520-537). In our setting, a new hotel owner chooses from among geographic locations based upon attributes of the locations.

The conditional logit model is specified as follows. The alternatives $j$ include the 578 zip codes in Texas with at least one hotel present. Each observation, therefore, has 578 rows of data. The observed dependent variable $Y_{i j}=1$ if zip code $j$ is chosen, and $Y_{i j}=0$ for the 577 zip codes not chosen. Assuming a linear relationship with the latent variable, we can write

$$
V_{i j}=b^{\prime} X_{i j}+e_{i j},
$$

where $X$ is a vector of independent variables of theoretical interest and control variables that are discussed in the next section. Positive values for the coefficients $b$ imply that zip codes possessing high values of the associated variables have a higher probability of being assigned the mandate. Negative coefficients can be interpreted as lower probabilities of being chosen.

We note that, of course, each entrepreneur wishing to open a new hotel is not actively considering all 578 zip codes as location choices. The entrepreneur may only be actively considering five or six sites, but the area may be much broader. One Gujarati hotel owner that we spoke to in our interviews told us that he searched within a 60-mile radius of a major urban center, implying that many zip codes were at least summarily considered. Importantly, the results of the conditional logit model are not biased if additional alternatives are included that are not actively considered by some. Parsons and Hauber (1998) conducted a systematic study of the effects of choice set size on conditional logit coefficients, and concluded that adding many alternatives with low likelihoods of being chosen had almost no effect.

\subsection{Description of Independent Variables}

Our independent variables of theoretical interest consist of a dummy variable for Gujarati hotel ownership and measures of Gujarati and non-Gujarati ownership in the vicinity of a hotel under observation. We use the owner surname to determine membership in the community of Gujarati immigrant entrepreneurs. Upon being shown a list of all surnames of hotel owners, two Gujaratis designated for us the following surnames to be Gujarati: Patel, Bhakta, Desai, Amin, Gandhi, Mistry, Thakor, Jallab, Shah, Govind, Zaveri, Rama, Rana, Mehta, Nathu, and Dalwad. Over 90\% of Gujarati hotels are owned by those with the surnames Patel and Bhakta. In our data, hotel owners are often listed as corporations. To identify Gujarati corporations, we used the Texas Incorporation data file compiled by the Secretary of State and compared the list of all corporations owned by Gujaratis (based on the same surnames as above) with the corporations that owned hotels. We consider any hotel that is incorporated and has a partner with a Gujarati surname to be a Gujarati-owned hotel. Finally, we note that due to ownership changes, the same hotel may be considered Gujarati-owned in some periods but not in others.

To operationalize the idea of firms with resources in the vicinity of each hotel under observation, we observe the ownership of the 10 closest hotels from the latitude and longitude coordinates of the hotel's actual location for the survival analysis. For the conditional logit analysis, we observe the ownership of the 10 closest hotels from each zip code's centroid, because the actual hotel had not yet been built. Among the 10 closest hotels, we include as separate variables the counts of branded-chain hotels (those likely to possess resources) and unbranded motels (those likely to possess few resources). These counts are further separated into hotels owned by Gujaratis and those owned by others. Importantly, these counts do not include other hotels belonging to the same owner as the hotel under observation. These counts capture the presence of Gujaratis with resources in the vicinity of the hotel under observation. The counts 
Figure 1 The 10 Closest Hotels to the Gujarati-Owned Pinn Road Motel (San Antonio, Texas)

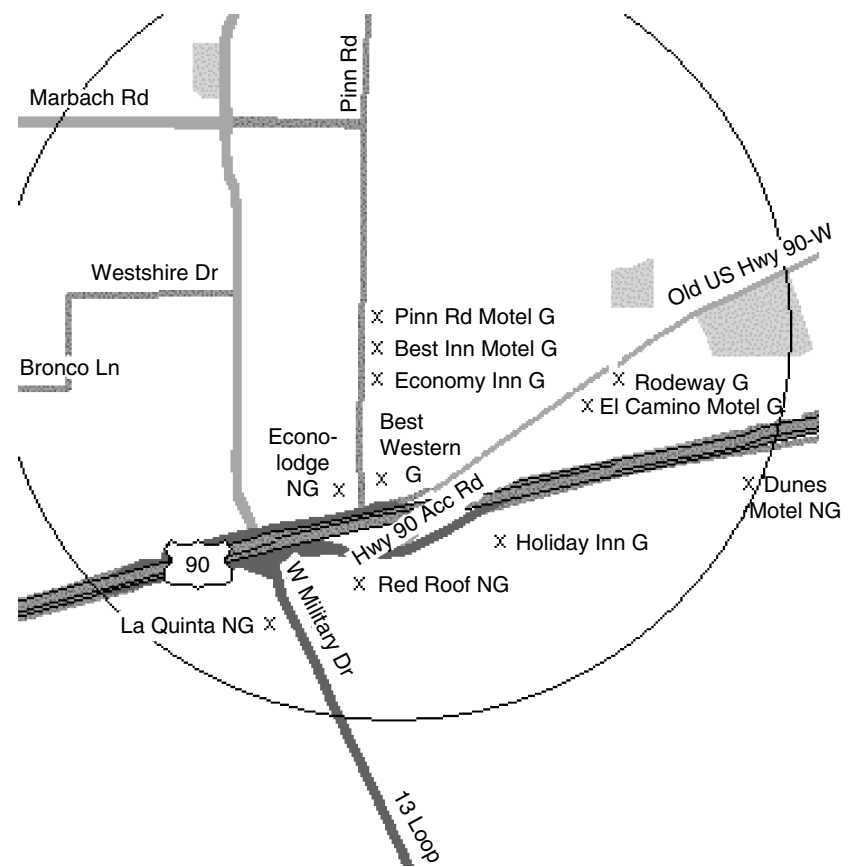

Notes. Proximate branded hotels owned by Gujaratis: Best Western + Holiday Inn + Rodeway $=3$. Proximate branded hotels owned by nonGujaratis: La Quinta + Red Roof + Econolodge $=3$. Proximate nonbranded hotels owned by Gujaratis: Best Inn Motel + El Camino Motel $=2$. Proximate nonbranded hotels owned by non-Gujaratis: Dunes Motel =1. Economy Inn is not counted because the word "motel" (or "motor hotel," "motor inn," or "motor lodge") does not appear in its name.

are then interacted with the Gujarati owner binary variable to assess whether only Gujaratis benefit from the proximate presence of other Gujaratis. Figure 1 illustrates how the count variables are calculated. In the figure, the Dunes Motel is the 10th closest hotel to the Pinn Road Motel, the hotel under observation. We draw a circle around the Pinn Road Motel with a radius equal to the distance to the Dunes Motel (0.7 miles). All hotels within this radius are included in one of the counts as long as they are either branded or have the word "motel" or "motor hotel" or "motor inn" in their name. The values for the count variables for the Pinn Road Motel are calculated at the bottom of Figure 1.

Table 3 shows us the distribution of Gujarati and non-Gujarati branded hotels in the proximity of (within the 10 closest hotels) Gujarati and non-Gujarati unbranded motels. For example, among the 612 unbranded Gujarati motels in existence in 1999, there were 196 with one Gujarati-owned branded hotel in their vicinity, and $209(99+72+30+8)$ with more than one. So, 65\% of all unbranded Gujarati motels in 1991 were able to enjoy some social capital from their more prosperous fellow group members.

We use the 10 closest hotels rather than a fixed distance limit because the ordinal distance to a high-resource immigrant entrepreneur group member is likely more important than the actual physical distance. If a low-resource member establishment is physically close to a high-resource member, but if other needy members are even closer to that resource-rich establishment, then the given establishment is less likely to receive benefit from the group's social capital. Completely exogenous administrative areas such as counties and metropolitan statistical areas vary too much in size to capture the opportunity set within which immigrant entrepreneurs can contribute to the social capital of the group. For example, Harris County (home of Houston) had 54 unbranded Gujarati-owned hotels and 53 unbranded non-Gujarati motels in 1999, while Deaf Smith County only had four unbranded motels, all owned by Gujaratis. To ensure our results were not sensitive to the "10th closest hotel" definition, we estimated regressions with other counts as well as zip codes. Results using alternative definitions are similar and are discussed in the robustness tests section.

Beyond these focal variables we control for the characteristics of each hotel and its owner. We include the logged distance from the hotel to its owner's headquarters to control for absentee owner effects. We also include the room count of each hotel because larger properties have been consistently shown to be more likely to survive (e.g., Ingram and Baum 1997).

Table 3 How Many Branded Chain Hotels Are Proximate (Within 10 Closest Hotels) to Unbranded Motels?

\begin{tabular}{|c|c|c|c|c|c|c|c|c|c|c|c|c|}
\hline & \multicolumn{6}{|c|}{$\begin{array}{l}\text { Number of Gujarati branded } \\
\text { chain hotels within } 10 \text { closest hotels }\end{array}$} & \multicolumn{6}{|c|}{$\begin{array}{l}\text { Number of non-Gujarati branded chain } \\
\text { hotels within } 10 \text { closest hotels }\end{array}$} \\
\hline & 0 & 1 & 2 & 3 & 4 & $5-10$ & 0 & 1 & 2 & 3 & 4 & $5-10$ \\
\hline $\begin{array}{l}449 \text { unbranded Gujarati } \\
\text { motels in } 1990\end{array}$ & 375 & 66 & 8 & & & & 96 & 196 & 98 & 67 & 48 & 34 \\
\hline $\begin{array}{l}794 \text { unbranded non-Gujarati } \\
\text { motels in } 1990\end{array}$ & 663 & 111 & 18 & 2 & & & 148 & 230 & 188 & 82 & 75 & 71 \\
\hline $\begin{array}{l}612 \text { unbranded Gujarati } \\
\text { motels in } 1999\end{array}$ & 207 & 196 & 99 & 72 & 30 & 8 & 137 & 135 & 136 & 97 & 35 & 70 \\
\hline $\begin{array}{l}505 \text { unbranded non-Gujarati } \\
\text { motels in } 1999\end{array}$ & 205 & 156 & 75 & 44 & 24 & 1 & 92 & 129 & 121 & 67 & 28 & 68 \\
\hline
\end{tabular}


We also include the count of other proximate hotels of the same owner (if any) and the owner's proximate experience (calculated as in Ingram and Baum 1997, using a square root discount factor) at the time of the founding or acquisition of the establishment under observation (congenital experience) and a dummy variable for left truncation (whether the hotel was opened before 1990). These variables are included for the survival analysis, but not for the conditional logit. In the latter case, these variables cannot be included because they are invariant across choice locations.

To control for demographics of each hotel's vicinity, we include the mileage distance to the 10th closest hotel (that serves as the radius for our hotel counts). Rural areas are likely to have larger distances to the 10th closest hotel. We include zip code residential population and per capita income (both from the 1990 census) to capture levels of potential demand. We also include the net addition of retail establishments in the two years previous to each spell to control for economic growth. In addition, we included the count of unbranded motel rooms in the zip code (but owned by others), as a measure of how much competition each unbranded motel faced. These variables are included for both the exponential hazard regressions and the conditional logit regressions. Descriptive statistics and correlations for all independent variables are included in Table 4 for the exponential hazard data set (the descriptive statistics for the conditional logit data set were so similar that they are not included separately).

\section{Results}

\subsection{Results of the Exponential Hazard Model-An Analysis of Failure Rates}

The results for the exponential hazard analysis of failure rates are shown in Table 5. There are four columns. The first column contains control variables only. The second column adds the "GujaratiOwned Motel" variable to test Hypothesis 1. The third column includes four counts of proximate hotels: Gujarati and non-Gujarati branded hotels, and Gujarati and non-Gujarati unbranded motels. The last column adds interaction terms with the Gujarati owner binary variable to test Hypotheses 2a-2c.

The results in the 2 nd through 4 th columns support Hypothesis 1-membership in an immigrant entrepreneur group helps low-resource establishments. Unbranded Gujarati motels survive substantially longer than unbranded non-Gujarati motels, based on the significance of the very first coefficient of each column. Hypothesis 2a-the social capital of the immigrant entrepreneur groups helps low-resource group members more than it helps low-resource nonmembers-is supported because the coefficient of the interaction term "Gujarati owner $\times$ proximate Gujarati hotels" is negative and statistically significant in the 4th column. Unbranded motels owned by Gujaratis have a lower probability of failure, relative to unbranded non-Gujarati motels, when proximate branded Gujarati-owned hotels are present. The failure rate comparison between the unbranded Gujarati motels and unbranded non-Gujarati motels is valuable because it demonstrates that the resources of branded Gujarati hotels only benefit those hotels lacking resources that are also Gujarati. This is not a spillover effect that applies to all proximate hotels, but a selective benefit from high-resource immigrant entrepreneur group members to less prosperous countrymen. Hotels owned by the same owner as that of the hotel under observation are not included in the proximate hotel counts, so our result here is not merely a multiunit ownership effect.

Note that the primary variable "Proximate hotels owned by Gujaratis" increases the likelihood of unbranded motel failure. The coefficient of the Gujarati interaction term is larger than that of the primary term, indicating that the net effect for Gujarati unbranded motels is survival enhancing. While the social capital theory discussed above does not predict a harmful effect for nongroup members, two possible mechanisms could be generating the higher failure rates for non-Gujarati unbranded motels in the vicinity of Gujarati branded hotels. First, the "Red Queen effect" has been shown to operate at the level of groups of organizations (Ingram and Simons 2002). In other words, the cooperation between group member organizations indirectly hurts nonmember organizations because the latter become relatively less competitive. Second, as discussed earlier, Gujarati chain hotels are more likely to belong to low-tier chains, and have the lowest prices, even within those chains. These findings suggest that the quality of unbranded motels in the vicinity of Gujarati chain hotels may be low, and that such hotels might be the most prone to failure. The social capital of the Gujarati group can help those unbranded establishments overcome the higher likelihood of failure faced by other unbranded motels.

Hypotheses $2 b$ and 2c-that low-resource group members benefit more from high-resource group members than from high-resource nonmembers or from low-resource nonmembers-require comparisons between the interaction effect of "Gujarati owner $\times$ proximate Gujarati hotels" versus "Gujarati owner $\times$ proximate non-Gujarati hotels" and versus "Gujarati owner $\times$ proximate unbranded Gujarati hotels." Table 6 displays the chi-square tests of size differences of these coefficients from Table 5.

Hypothesis $2 \mathrm{~b}$ is supported, as demonstrated by the statistical significance of the first chi-square test 


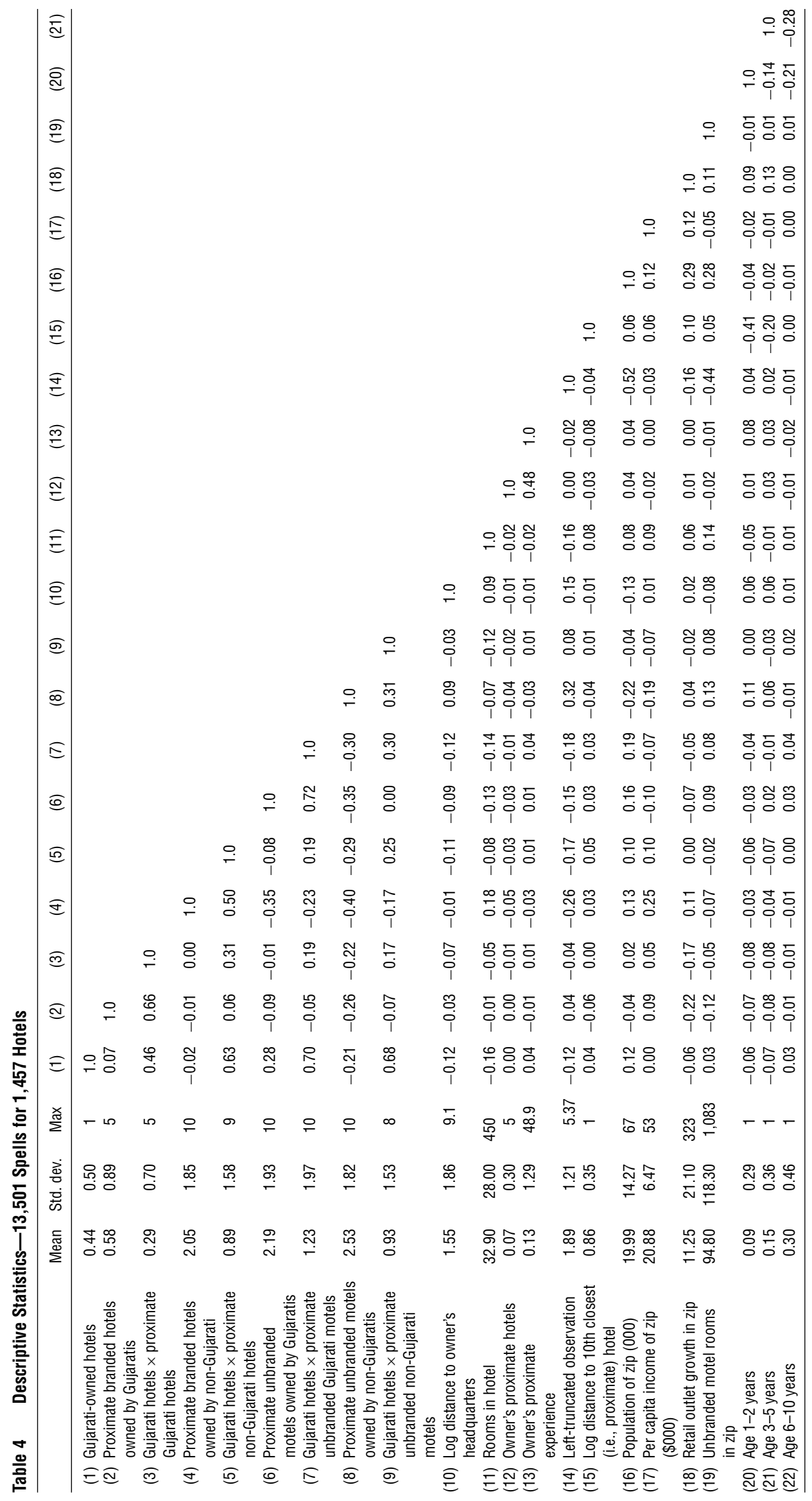


Table 5 Exponential Hazard Models Predicting 298 Failures Among 1,457 Unbranded Motels

(1) Gujarati-owned unbranded motels

(2) Proximate branded hotels owned by Gujaratis

(3) Gujarati owner $\times$ proximate Gujarati hotels (Hypothesis 2a)

(4) Proximate branded hotels owned by non-Gujaratis

(5) Gujarati owner $\times$ proximate non-Gujarati hotels (Comparison for Hypothesis 2b)

(6) Proximate unbranded motels owned by Gujaratis

(7) Gujarati owner × proximate unbranded Gujarati motels (Comparison for Hypothesis 2c)

(8) Proximate unbranded motels owned by non-Gujaratis

(9) Gujarati owner $\times$ proximate unbranded non-Gujarati motels

(10) Log distance to owner's headquarters

(11) Number of rooms

(12) Same owner's proximate hotels

(13) Same owner's proximate experience

(14) Left truncated observation

(15) Log distance to 10th closest (i.e., proximate) hotel

(16) Population of zip

(17) Per capita income of zip

(18) Retail outlet growth in zip

(19) Unbranded motel rooms in zip

(20) Age 1-2 years

(21) Age 3-5 years

(22) Age 6-10 years

Chi squared

$\begin{array}{cccc} & & & (0.112) \\ 0.155^{* *} & 0.148^{* *} & 0.155^{* *} & 0.154^{* *} \\ (0.027) & (0.027) & (0.027) & (0.027) \\ -0.009^{* *} & -0.011^{* *} & -0.012^{* *} & -0.012^{* *} \\ (0.003) & (0.003) & (0.003) & (0.003) \\ 0.072 & 0.022 & -0.036 & -0.047 \\ (0.213) & (0.210) & (0.212) & (0.212) \\ -0.016 & 0.005 & 0.009 & 0.012 \\ (0.063) & (0.061) & (0.061) & (0.063) \\ 0.031 & 0.084 & 0.204 & 0.220 \\ (0.201) & (0.201) & (0.203) & (0.204) \\ 0.000 & 0.000 & 0.000 & 0.000 \\ (0.000) & (0.000) & (0.000) & (0.000) \\ 0.004 & 0.006 & 0.005 & 0.005 \\ (0.005) & (0.005) & (0.005) & (0.005) \\ -0.015 & -0.015 & -0.021^{*} & -0.022^{*} \\ (0.010) & (0.009) & (0.010) & (0.010) \\ -0.024^{* *} & -0.026^{* *} & -0.023^{* *} & -0.023^{* *} \\ (0.003) & (0.003) & (0.003) & (0.003) \\ 0.001 & 0.000 & 0.001 & 0.001 \\ (0.001) & (0.001) & (0.001) & (0.001) \\ 0.416 & 0.409 & 0.497^{+} & 0.470^{+} \\ (0.284) & (0.284) & (0.284) & (0.285) \\ 0.586^{* *} & 0.586^{* *} & 0.635^{* *} & 0.619^{* *} \\ (0.174) & (0.173) & (0.175) & (0.175) \\ 0.139 & 0.234^{+} & 0.252^{+} & 0.216 \\ (0.139) & (0.140) & (0.141) & (0.141) \\ 121.4 & 159.6 & 178.7 & 188.8\end{array}$

Notes. Positive coefficients indicate greater likelihood of failure.

Two-tailed tests: ${ }^{+} p<0.10 ;{ }^{*} p<0.05 ;{ }^{* *} p<0.01$

in Table 6. The coefficient of the "Gujarati owner $\times$ proximate Gujarati hotels" interaction term variable in Table 5 is significantly larger than that of the "Gujarati owner $\times$ proximate non-Gujarati hotels" interaction term. This statistically significant greater effect demonstrates that the reduction in failure rates to unbranded Gujarati motels, relative to unbranded non-Gujarati motels, is not caused by the presence of just any branded chain hotel. The branded hotels must be owned by Gujaratis.

Hypothesis 2c is also supported. The coefficient of the "Gujarati owner × proximate Gujarati hotels" interaction term variable is significantly larger than that of the "Gujarati owner $\times$ proximate unbranded Gujarati motels" interaction term, as demonstrated
Table 6

Differences Between Coefficients from Column 4 of Table 5

\begin{tabular}{lcc}
\hline & Coefficient & Chi-square (1) \\
\hline $\begin{array}{l}\text { Gujarati owner } \times \text { proximate } \\
\text { Gujarati hotels }\end{array}$ & -0.367 & \\
$\begin{array}{l}\text { Gujarati owner } \times \text { proximate } \\
\text { non-Gujarati hotels }\end{array}$ & 0.019 & \\
$\begin{array}{l}\text { Hypothesis 2b: coeff }(3)>\text { coeff }(5) \\
\text { Gujarati owner } \times \text { proximate } \\
\text { unbranded Gujarati motels }\end{array}$ & 0.066 & $4.52^{*}$ \\
Hypothesis 2c: coeff $(3)>\operatorname{coeff}(7)$ & & \\
\hline
\end{tabular}

Note. Chi-square test: ${ }^{*} p<0.05$; ${ }^{* *} p<0.01$.

by the significance of the second chi-squared test in Table 6. The proximate presence of branded Gujarati hotels is far more beneficial to the unbranded Gujarati motel owner than is the presence of other unbranded Gujarati motels in his or her vicinity. This finding supports the idea that resources are required for an immigrant entrepreneur to have the ability to contribute to the group's social capital and to help other group members. The proximate presence of unbranded Gujarati motels does not significantly increase or decrease the likelihood of failure of other unbranded Gujarati motels, relative to their effect on unbranded non-Gujarati motels.

Among the control variables, larger hotels are more likely to survive longer, as are hotels whose headquarters are more proximate. This interesting result indicates a cost to absentee ownership. Hotels will also survive longer in areas with high levels of retail growth.

To summarize, the combination of support for Hypotheses 2a-2c strongly suggests that immigrant entrepreneur group members without resources only benefit from the presence of group members with resources. By separating group members from proximate nongroup members, we isolated empirically a social-capital-based group effect from any general agglomeration or spillover effect that would arise from the presence of branded chain hotels owned by anyone, or simply in more profitable or high-growth areas.

\subsection{Results of the Conditional Logit Model- An Analysis of Location Choice}

Hypotheses 3a-3c, which predicted that low-resource member establishments will locate close to highresource member establishments but not to highresource nonmembers or low-resource members, are tested in Table 7 using a conditional logit model of location choice. While the hypotheses are not supported, interesting results emerge. In particular, the coefficient of the "Gujarati owner $\times$ proximate unbranded Gujarati motels" is positive and significant, which suggests that the presence of unbranded 
Table 7 Conditional Logit Model (Location Choices of New Unbranded Motels)

(2) Proximate branded hotels owned by Gujaratis

(3) Gujarati owner $\times$ proximate Gujarati hotels (Hypothesis 3a)

(4) Proximate branded hotels owned by non-Gujaratis

(5) Gujarati owner $\times$ proximate non-Gujarati hotels (Comparison for Hypothesis $3 b$ )

(6) Proximate unbranded motels owned by Gujaratis

(7) Gujarati owner $\times$ proximate unbranded Gujarati motels (Comparison for Hypothesis 3c)

(8) Proximate unbranded motels owned by non-Gujaratis

(9) Gujarati owner $\times$ proximate unbranded non-Gujarati motels

(12) Same owner's proximate hotels

(13) Same owner's proximate experience

(15) Log distance to 10th closest (i.e., proximate) hotel

(16) Population of zip

(17) Per capita income of zip

(18) Retail outlet growth in zip

(19) Unbranded motel rooms in zip

Chi squared

Notes. $N=178$ hotels (67 Gujarati) choosing among 578 zip codes. Variables 1,11 , and 14 could not be included because they do not differ within the set of alternatives for each owner. Variable 10 is not included because it is often endogenous to the choice of location.

Two-tailed tests: ${ }^{+} p<0.10 ;{ }^{*} p<0.05 ;{ }^{* *} p<0.01$.

Gujarati motels increases a location's attractiveness to Gujarati entrepreneurs. Given the strong support for Hypotheses 2a-2c, which predicted that low-resource member firms benefit more from the presence of high-resource members than from other establishment types, this opposite result to Hypothesis $3 c^{\prime}$ s expectation is intriguing. We discuss the implications below.

Among the control variables in the conditional logit regressions, we find that owners locate in the vicinity of their existing hotels (if they have any). More interesting is the fact that they are more likely to locate in low-income areas and areas where the logged distance to the 10th closest hotel is greater, which is the case in more rural areas. These findings suggest that the unbranded motel retains a niche in these markets typically overlooked by the large branded chains.

\subsection{Robustness Tests}

Before settling on our main results, we conducted several alternate tests. While presenting results using the closest 10 hotels as the relevant vicinity for the hotel under observation, we also varied the count downwards to the closest 5 hotels and upwards to the closest 15, 20,30, and 40 hotels, and also used the counts in each hotel's zip code. The survival results (Hypotheses 1 and 2a-2c) presented hold for the range between 5 and 15 hotels, and marginal significance remained when using the zip code. The stability of results in the 5 to 15 range suggests that the closest 20, 30, or 40 hotels is too broad a range. While the distance to the 30th closest hotel may not be too far for high-resource owners to have the opportunity to understand the needs of other owners within their ethnic community, there are likely to be other needy establishments closer to the high-resource owner that will receive the benefits. The conditional logit results that Gujaratis are attracted to locations with other unbranded Gujarati motels are also robust between the range of 5 and 20 hotels, as well as to the case of zip codes.

In addition, we split the Texan hotel population into metro and rural subsamples (we defined metro areas as Texas' 10 most populous counties, which contain the state's major cities). We found that Hypotheses 1 and $2 a-2 c$ hold for the metro subsample, and that Hypotheses 1, 2a, and 2b hold for the rural subsample. Hypothesis $2 c$ is very close to significant for the latter subsample $(p<0.113)$. We find particularly interesting the fact that the social capital of the immigrant group remains important in metro areas where the individual entrepreneurs should have more opportunity to obtain resources from the native population.

\section{Discussion}

\subsection{Contribution to the Literature}

Our study provides interesting findings regarding heterogeneity of contribution and benefits within groups of immigrant entrepreneurs. Both opportunity and ability enhance a group member's contributions to and benefits from the group's social capital. Members of the group that possess more resources are less likely to be helped by others in the group, because the others are unlikely to possess resources that the highresource group members would find valuable. In this sense, our findings are very consistent with those of other research streams on other types of interaction between firms where resource heterogeneity has been explicitly considered. Ahuja (2000) and Shaver and Flyer (2000), for example, find that firms with their own resources are less likely to seek alliances and agglomeration opportunities, respectively. In those cases, similar to ours, firms with few resources benefit most from cooperation while those with abundant resources contribute the most. The result also 
complements sociological work on entrepreneurship that has found performance benefits for entrepreneurs able to affiliate with high-status venture capitalists (Stuart et al. 1999). Yet, unlike those instances, the immigrant entrepreneurs are well aware of their contributions to others in their group, and do not appear to try to avoid such contributions (as do the firms in Ahuja 2000 and Shaver and Flyer 2000), nor do they charge a premium as do the high-status venture capitalists (Hsu 2004). In fact, based on our interviews, established high-resource Gujarati hotel owners were proud of being able to contribute without any compensation, consistent with the ideas of shared values and shared destiny.

Our results presented here for one large group of immigrant entrepreneurs complements work about performance heterogeneity within the large industrial business groups such as chaebols and keiretsus (e.g., Guillen 2000, Khanna and Rivkin 2001, Lincoln et al. 1996) as well as Israeli kibbutzim (Ingram and Simons 2002). Indeed, the results here broaden the scope of applicability for that literature. Like our group of immigrant entrepreneurs, industrial business groups often revolve around family and ethnic ties (Granovetter 1994). Unlike the small-enterprise level of the Gujaratis, large industrial business groups include the cross-holding of equity and substantial employment of workers from outside the group. Yet, the basic principle underlying our hypotheses-that ability and opportunity matter for contributions to and benefits from social capital-should hold for any group bound by norms other than an incentive to maximize individual profits.

Given the benefits for a Gujarati unbranded motel to be in the vicinity of a branded Gujarati hotel, the result that Gujarati entrepreneurs are likely to locate their unbranded motels primarily in the vicinity of other unbranded Gujarati motels is surprising. This result suggests that the location is not chosen to increase potential personal benefits via proximate high-resource group members. It also suggests that the location choice is not made merely to enjoy the social benefits of many proximate group members because these benefits should arise from locating proximately to any type of Gujarati establishment, high or low resource. Finally, the result reduces the possibility that these foundings are spin-offs from existing firms (e.g., Klepper and Sleeper 2002) that locate proximately to the entrepreneur's previous employer (Sorenson and Audia 2000). While some Gujaratis do "spin-off" by first working for the hotel of another Gujarati, the employing hotel is typically a branded property that requires additional staff. The unbranded motels are often literal "mom and pop" operations that only require one or two additional part-time staff (Kalnins and Chung 2001, p. 34). Of the 16 Gujarati hotel owners that we interviewed, only three had previously worked for branded chain hotels.

Why then should Gujaratis locate their unbranded motels proximate to other unbranded Gujarati motels? Baum et al. (2000) found that firms were more likely to imitate similar others than large, visible firms in spatial location decisions. Our findings suggest that the Gujarati entrepreneurs, too, are locating mimetically in the vicinity of the most socially similar others-other unbranded Gujarati motels. Alternatively, the cost of locating in an area with branded properties may be prohibitive for entrepreneurs seeking to found an unbranded motel. We note that our split of Gujarati hotels into high- and low-resource subgroups clarifies some insignificant results presented by Kalnins and Chung (2001). In that study, the Gujaratis were not split into the two groups and no localized clustering was found to occur.

Our results regarding the importance of group membership and geographical proximity complement the large and growing literature of social networks (see, e.g., Burt 2000 for an extensive review). For example, Bruderl and Preisendorfer (1998) highlight the benefits of family members to entrepreneurs, while Ingram and Roberts (2000) demonstrate the importance of friendship ties for hotel management. Similarly, Starr and MacMillan (1990) stress the importance of ties for procuring resources. The geography-based arguments presented here are similar to the network literature's arguments that individuals within a network benefit heterogeneously based on their network position. Much like geographical proximity, a network tie provides an opportunity to help fellow group members. We believe that immigrant entrepreneur groups would be an interesting setting for a thorough study of friendship and network ties both within and outside the group. Based on our interviews, groups such as the Gujaratis clearly have networks of family and friends within the industry that can contribute to social capital above and beyond simple group membership, and even when outside their geographical vicinity.

\subsection{Caveats}

Before concluding, we note two caveats. First, while our results are consistent with Hypothesis 1, the business establishments of immigrant entrepreneur group members may survive longer than their indigenously owned counterparts for reasons not directly resulting from membership in the immigrant group. Immigrant group members often possess higher levels of human capital (such as education) than their competition because they may not have the wide range of opportunities that educated locals possess (Light and Bonacich 1988, Sanders and Nee 1996). We do 
not discount this explanation. In fact, we believe that it complements our explanations of success based on social capital. We do note, however, that human capital explanations do not exist for Hypotheses 2a-2c: enhanced survival in the vicinity of other group members cannot be explained without explicit group effects.

Second, while the results presented in this paper provide systematic statistical evidence regarding the economic importance of social capital within groups of immigrant entrepreneurs, the results here are limited to one U.S. state, one ethnic group, and one industry. Nevertheless, Texas is a large state with a wide variety of location types (e.g., urban, rural, major highways, and coastal resorts) that appear representative of those existing throughout the United States. Further, our interviews with Gujaratis indicated that their behavior conforms to that expected by social capital theory, also suggesting generalizability. While the hotel industry has some idiosyncrasies (low entry costs and the ability to operate independently or as a part of a franchised branded chain), it is likely that these structural features have allowed a group of immigrant entrepreneurs to flourish and even dominate the industry. As the Gujaratis have accumulated resources they have remained in the industry, but from the more profitable and powerful vantage of the franchised branded chains.

\section{Conclusion}

Groups within a capitalist economy that can develop and maintain local social capital have been suggested as a vital source of entrepreneurial talent, even in developed nations (Putnam 1995, 2000). We assessed the importance of a group of immigrant entrepreneurs within the lodging industry, arguing that group membership provides critical resources for struggling members, thereby improving likelihood of establishment survival, relative to that enjoyed by nonmembers. While controlling for agglomerationbased benefits that do not require group membership to accrue, we developed and tested hypotheses that survival benefits enjoyed by group members are the result of social capital. Some firms may contribute to and benefit from the group's social capital differently due to differences in their ability and opportunity. Greater stocks of social capital enable firms to initiate social exchange. Firms with few resources are unlikely to be able to help their fellow group members even if they had the motivation and opportunity. Also, geographical proximity is important for the opportunity to conduct social exchanges. Consistent with these arguments, we found that proximate group member firms with resources increased the likelihood of survival of other group member firms in their vicinity significantly more than the proximate presence of high-resource nongroup members. These results reinforce the importance of social capital not only for immigrant entrepreneurs but also more generally for any entrepreneurs that have the ability of participating in ethnic, professional, religious, or social groups.

\section{Acknowledgments}

The authors thank Paul Adler, Bob Gibbons, Anand Swaminathan, and Michele Williams for helpful comments. We also acknowledge comments from seminar participants at New York University, the Wharton School, Cornell University, and the University of Illinois as well as session participants at the Harvard Business School Strategy Conference, the Management Science Entrepreneurship Conference at Case Western, the West Coast Technology Entrepreneurship Conference at the University of Washington, and the American Sociological Association 2004 Annual Meeting, San Francisco, CA.

\section{References}

Adams, J., A. Jaffe. 1996. Bounding the effects of R\&D: An investigation using matched establishment-firm data. RAND J. Econom. 27 700-721.

Adler, P., S. Kwon. 2002. Social capital: Prospects for a new concept. Acad. Management Rev. 27 18-40.

Ahuja, G. 2000. The duality of collaboration: Inducements and opportunities in the formation of inter-firm linkages. Strategic Management J. 21 317-343.

Aldrich, H., R. Waldinger. 1990. Ethnicity and entrepreneurship. Annual Rev. Sociol. 16 111-135.

Aldrich, H., C. Zimmer. 1986. Entrepreneurship through social networks. D. Sexton, R. Smelser, eds. The Art and Science of Entrepreneurship. Ballinger, Cambridge, MA, 3-23.

Aldrich, H., T. Jones, D. McEvoy. 1984. Ethnic advantage and minority business development. R. Ward, R. Jenkins, eds. Ethnic Communities in Business. Cambridge University Press, New York, 189-210.

Bates, T. 1994. Social resources generated by group support networks may not be beneficial to Asian immigrant-owned small businesses. Social Forces 72(3) 671-689.

Baum, J., H. Haveman. 1997. Love thy neighbor? Differentiation and agglomeration in the Manhattan hotel industry, 1898-1990. Admin. Sci. Quart. 42 304-339.

Baum, J., S. Li, J. Usher. 2000. Making the next move: How experiential and vicarious learning shape the locations of chains' acquisitions. Admin. Sci. Quart. 45 766-801.

Bonacich, E., J. Modell. 1980. The Economic Basis of Group Solidarity: Small Business in the Japanese American Community. University of California Press, Berkeley, CA.

Bourdieu, P. 1986. Forms of capital. J. Richardson, ed. Handbook of Theory and Research for the Sociology of Education. Greenwood Press, Westport, CT, 241-260.

Bruderl, J., P. Preisendorfer. 1998. Network support and the success of newly founded businesses. Small Bus. Econom. 10(3) 213-225.

Burt, R. 2000. The network structure of social capital. R. Sutton, B. Staw, eds. Research in Organizational Behavior, Vol. 22. JAI Press, Greenwich, CT, 345-423.

Canina, L., C. Enz, J. Harrison. 2005. Agglomeration effects and strategic orientations: Evidence from the U.S. lodging industry. Acad. Management J. 48 565-581.

Chung, W., A. Kalnins. 2001. Agglomeration effects and performance: A test of the Texas lodging industry. Strategic Management J. 22 969-997. 
Coleman, J. 1990. Foundations of Social Theory. Harvard University Press, Cambridge, MA.

Geertz, C. 1962. The rotating credit association: A "middle rung" in development. Econom. Development Cultural Change 1 241-263.

Granovetter, M. 1994. Business groups. N. J. Smelser, R. Swedberg, eds. Handbook of Economic Sociol.. Princeton University Press, Princeton, NJ.

Greene, W. 1998. LIMDEP 7.0 User's Manual, Revised ed. Econometric Software, Inc., Plainview, NY.

Greensboro News and Record. 1995. Indian immigrants infuse motel industry. (October 1) E7.

Greve, H. 1995. Jumping ship: The diffusion of strategy abandonment. Admin. Sci. Quart. 40 444-474.

Greve, H. 2000. Market niche entry decisions: Competition, learning and strategy in Tokyo banking, 1894-1936. Acad. Management J. 43 816-836.

Guillen, M. 2000. Business groups in emerging economies: A resource-based view. Acad. Management J. 43 362-380.

Gulati, R. 1995. Does familiarity breed trust? The implications of repeated ties for contractural choice in alliances. Acad. Management J. 38 85-112.

Guo, G. 1993. Event-history analysis of left-truncated data. Sociol. Methodology 23 217-242.

Hamilton, B. 2000. Does entrepreneurship pay? An empirical analysis of the returns to self-employment. J. Political Econom. 108 604-631.

Haveman, H. 1993. Follow the leader: Mimetic isomorphism and entry into new markets. Admin. Sci. Quart. 38 593-627.

Hsu, D. 2004. What do entrepreneurs pay for venture capital affiliation? J. Finance 59 1805-1844.

Ingram, P. 1996. Organizational form as a mechanism for generating credible commitment: The evolution of naming strategy in the U.S. hospitality industry. Strategic Management J. 17(Summer) $85-98$.

Ingram, P., J. Baum. 1997. Chain affiliation and the failure of Manhattan hotels, 1898-1980. Admin. Sci. Quart. 41 68-102.

Ingram, P., P. Roberts. 2000. Friendship among competitors in the Sydney hotel industry. Amer. J. Sociol. 106 387-423.

Ingram, P., T. Simons. 2002. The transfer of experience in groups of organizations: Implications for performance and competition. Management Sci. 48 1517-1533.

Kalnins, A., W. Chung. 2001. Ethnic links, location choice and performance: A test of the rural motel industry. J. Baum, H. Greve, eds. Advances in Strategic Management, Vol. 18. JAI Press, Oxford, UK, 31-51.

Khanna, T., J. Rivkin. 2001. Estimating the performance effects of business groups in emerging markets. Strategic Management J. 22(1) 41-51.

Klepper, S., S. Sleeper. 2002. Entry by spinoffs. Working paper, Carnegie Mellon University, Pittsburgh, PA.
Light, I. 1972. Ethnic Enterprise in America. University of California Press, Berkeley, CA.

Light, I., E. Bonacich. 1988. Immigrant Entrepreneurs: Koreans in Los Angeles, 1965-1982. University of California Press, Berkeley, CA.

Lincoln, J., M. Gerlach, C. Ahmadjian. 1996. Keiretsu networks and corporate performance in Japan. Amer. Sociol. Rev. 61 67-88.

Marshall, A. 1920. Principles of Economics. MacMillan, London, UK.

McDermott, P., M. Taylor. 1982. Industrial Organisation and Location. Cambridge University Press, Cambridge, UK.

Millman, J. 1997. The Other Americans: How Immigrants Renew Our Country, Our Economy, and Our Values. Viking, New York.

Ong, P. 1981. An ethnic trade: Chinese laundries in early California. J. Ethnic Stud. 8 95-113.

Parsons, G., A. Hauber. 1998. Spatial boundaries and choice-set definition in a random utility model of recreation demand. Land Econom. 74 32-48.

Portes, A., J. Sensenbrenner. 1993. Embeddedness of immigration: Notes on the social determinants of economic action. Amer. J. Sociol. 98 1320-1350.

Powell, W., D. White, K. Koput, J. Owen-Smith. 2004. Network dynamics and field evolution: The growth of interorganizational collaboration in the life sciences. Amer. J. Sociol. 110 1132-1205.

Putnam, R. 1995. Bowling alone: America's declining social capital. J. Democracy 6 65-78.

Putnam, R. 2000. Bowling Alone: The Collapse and Revival of American Community. Touchstone, New York.

Sanders, J., V. Nee. 1996. Social capital, human capital, and immigrant self-employment. Amer. Sociol. Rev. 61 231-249.

Schumpeter, J. 1934. Capitalism, Socialism, and Democracy. Harper and Row, New York.

Shane, S., S. Venkatraman. 2000. The promise of entrepreneurship as a field of research. Acad. Management J. 25 217-226.

Shaver, J., F. Flyer. 2000. Agglomeration economies, firm heterogeneity, and foreign direct investment in the United States. Strategic Management J. 21 1175-1193.

Sorenson, O., P. Audia. 2000. The social structure of entrepreneurial activity: Geographic concentration of footwear production in the United States, 1940-1989. Amer. J. Sociol. 106 224-262.

Starr, J., I. MacMillan. 1990. Resource cooptation via social contracting: Resource acquisition strategies for new ventures. Strategic Management J. 11(Special issue) 79-92.

Stata Corp. 2001. Stata 7 Reference Q-St. Stata Press, College Station, TX.

Stuart, T., H. Hoang, R. Hybels. 1999. Interorganizational endorsements and the performance of entrepreneurial ventures. Admin. Sci. Quart. 44 315-349.

Uzzi, B. 1996. The sources and consequences of embeddedness for the economic performance of organizations: The network effect. Amer. Sociol. Rev. 61 674-698. 